\title{
Review of the strengths and weaknesses of risk matrices
}

\author{
Mustafa Elmontsri \\ Department of Primary Care and Public Health, School of Public Health, Imperial College London \\ St Dunstan's Road, London, W6 8RP, United Kingdom \\ E-mail: m.elmontsri10@imperial.ac.uk \\ www.imperial.ac.uk
}

Received 5 July 2013

Accepted 29 January 2014

\begin{abstract}
Risk assessment and risk matrices are powered tools used in risk management and help guide in the process of decision-making in organisations. Nevertheless, risk matrices have their own weaknesses and strengths. This paper provides a critical overview of the development and use of risk matrices in different field with an example of the risk matrix used by the National Health Service (NHS) in England. Risk matrices are helpful tools for risk assessment as they use quantitative measures to ensure consistent method of determining risk but organisations should adjust the design and size of risk matrices to suit their needs.
\end{abstract}

Keywords: Risk Assessment Matrix, Risk Matrices, NHS risk matrix, quantitative risk matrix

\section{Introduction}

All over the world, nations and organisations are attempting to reduce risks, to improve safety and to extend lives. Indeed risk reduction has become a principle goal of modern governments and almost in every organisation. It is obvious that people, including government officials, often lack risk-related information. They often know little about the nature and magnitude of the risks at issue, and they often know little about the various consequences of risk reduction (Sunstein, 2002).

Since risk cannot be eliminated, the main problems people face, individually and collectively, are how much risk they should live with and how they should go about managing the risk. If a set of strategies have been chosen that will allow the abatement of a particular risk, the question of what level of risk should be chosen arises. If abating the risk costs nothing, the obvious answer is zero, get rid of the risk. But risk abatement almost always does cost money and time (Glickman and Gough, 1990).

To answer these questions, analytical tools and risk ranking schemes must be used to distinguish lower risk activities / incidents from higher risk activities / incidents. One of the risk ranking methodologies is known as the risk assessment matrix.

\section{Risk Management}

Risk management is the process of assessing risks and taking steps to either eliminate or to reduce them (as far as is reasonably practicable) by introducing control measures. Risk management refers to the process of reducing the risks to a level deemed tolerable by society and to assure control, monitoring, and public communication (Morgan, 1990).

There are more questions than answers when people talk about risks. The career of the term 'risk' is a rather recent phenomenon, however (Fischhoff et al., 1984), states that, "risk has always been part of human 
existence and the field of risk research started as early as human beings started to reflect the possibility of their own deaths and contemplated actions to avoid dangerous situations".

The International Risk Governance Council (IRGC) has developed a framework (Figure 1 below), which distinguishes between analysing and understanding a risk - for which risk appraisal is the essential procedure - and deciding what to do about a risk - where risk management is the key activity (IRGC white paper, 2005).

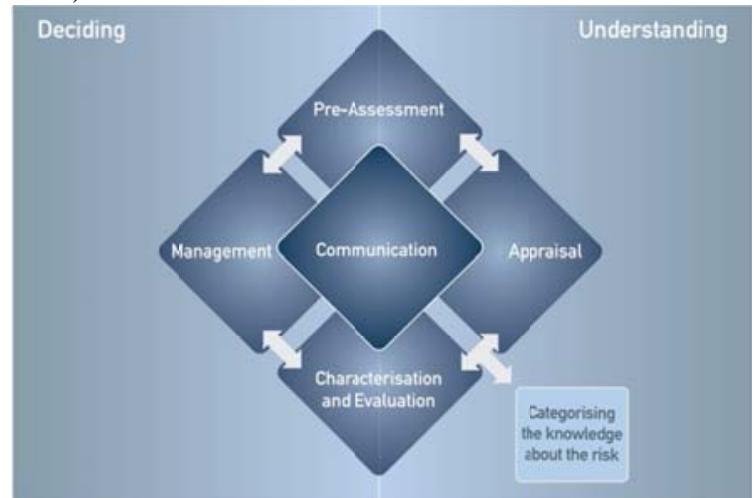

Fig. 1.IRGC’s risk governance framework (IRGC, 2005)

\section{Definition of Risk}

There is no commonly accepted definition for the term risk - neither in the sciences nor in public understanding. All risk concepts have one element in common, however: there is a distinction between reality and possibility (Renn, 1998).

The definition of risk according to The Royal Society (1992) is "the probability that a particular adverse event occurs during a stated period of time or results from a particular challenge. As a probability in a sense of statistical risk obeys all the formal laws of combining probabilities”

Fischhoff et al (1984), states that the definition of risk, like that of any other key term in policy issues, is inherently controversial. The choice of definition can affect the outcome of policy debates, the allocation of resources amongst safety measures, and the distribution of political power in society.

\section{Risk Assessment}

All of the people, things, activities and places which have to be managed can, in some circumstance, be a hazard. It follows therefore, that unless it is known exactly what is being managed it will not be possible to identify all of the sources of hazards (Boyle, 2002).

According to Boyle, one of the problems with hazard identification is that a large number of hazards will be identified, with some obviously more serious than others.

The mathematical tools for risk assessment were developed more than a century before actual risk analyses were performed on technical systems (Renn, 1998). Risk assessment is the scientific process of defining the components of risk in precise, predominantly quantitative terms. It is argued that in technical risk assessments, this means specifying what is at stake, calculating the probabilities for (un)wanted consequences, and aggregating both components by multiplying the probabilities by the magnitude of the effects (Kolluru and Brooks, 1995).

Risk assessment techniques vary from purely qualitative approaches through a regime of semi-qualitative to the more traditional quantitative. Altenbach (1995), argues that constraints such as time, money, manpower, skills, management perceptions, risk result communication to the public, and political pressures all affect the manner in which risk assessment are carried out.

Cox (2005), states that when quantitative approach is applied to risk assessments, it can be considered to produce subjective and very limited relative sense of the risk only. He argues that qualitative judgments may rank the risk from one scenario or group of scenarios to be greater than some other scenario or group of scenarios. When all the scenarios from a system are included in the ranking, the ranking can only be done subjectively.

Whereas quantitative risk assessment, according to (Cox, 2005), the risk from each scenario is estimated numerically, allowing the analyst to determine not only risk relative to all scenarios in the system, but absolute risk measured on whatever scale of units are chosen.

These determinations can be made objectively using numerical scales. Jeffery (2006) states the semiquantitative risk assessment may use some numbers, mainly in the form of board ranges of frequency or consequence levels.

In 2008, Tony Cox wrote about serious technomathematical problems associated with a widely used risk tool often referred to as a consequence probability matrix or, more simply, a "risk matrix. Generally, these devices come in the form of qualitative or semi- 
quantitative instruments in which hazards are first identified and then allocated to a box on a twodimensional grid for which one axis measures the likelihood of a specific incident and the other the potential severity of consequences.

The issues identified by Cox are certainly not confined to the United States, and indeed usage of risk matrices has spread in the United Kingdom and Europe from industry to all manner of public and private agencies ranging from hospitals to small- and medium-sized enterprises, local and central government bodies, and professional institutions

\subsection{Risk assessment matrix}

A common method used for risk ranking utilises risk matrices; these are typically $4 \times 4$ or $5 \times 5$ matrices, having event consequences along one axis and event frequency along the other. Each block on the risk matrix represents some level of risk, and blocks presenting similar risk are often grouped together into one of four or five risk regions (Altenbach\&Brereton, 1998)

Risk matrix is defined as "a mechanism to characterise and rank process risks that are typically identified through one or more multifunctional reviews (e.g. process hazard analysis, audits, or incident investigation" (Markowski and Mannan, 2008), and is also defined by Cox (2008) as "a table that has several categories of "probability," "likelihood," or "frequency" for its rows (or columns) and several categories of "severity," "impact," or "consequences” for its columns (or rows, respectively)”.

In most cases, the frequency axis of the matrix has numerical values associated with it, typically spanning several orders of magnitude. Often, the consequence axis is based on a qualitative scale, where consequences are judgment based. However, the consequence scale generally has implicit quantitative values associated with it, which may or may not be recognised. Risk regions are often arbitrarily assigned (or assigned on the basis of symmetry). This presents a problem in that if the blocks of the risk matrix are incorrectly grouped, then incorrect conclusions can be drawn about the relative risk presented by events at a facility (Woodruff, 2005).Three types of risk matrices are commonly used for risk ranking. A purely qualitative risk matrix will have its blocks defined in descriptive or qualitative terms. A purely quantitative risk matrix has its blocks defined in measurable or quantitative terms. Relative or absolute numerical scales are used on quantitative matrices, whereas scales on qualitative matrices are relative but not numerical. The third type of risk matrix is a hybrid: a semi-quantitative matrix with one scale (usually frequency) expressed quantitatively, while the other scale is expressed qualitatively (Emblemsvag and Kjølstad, 2006).iNTeg-Risk (2008) clearly states the importance of using scoring systems in risk assessment and management which generally requires the application of specific scores or scales. They highlight that in practical use, conventions such as using $5 \times 5$ risk matrices and/or a colour-code can be beneficial

\subsubsection{Qualitative risk matrix}

The qualitative risk matrix is basically task and or hazard analysis with some relative judgments made in order to categorise the hazards. When the $3 \times 3$ matrix is used, both the frequency and consequence of each accident scenario are then estimated on simple relative scales, such as low, medium and high. The risk for each scenarios is the product of the frequency rating and consequence rating, this indicates that the qualitative risk in this case falls into nine distinct regions or frequency $\mathrm{x}$ consequence pairs: Low $\mathrm{x}$ Low, Low $\mathrm{x}$ Medium, Low x High, Medium x Low, Medium x Medium, Medium $x$ High, High $x$ Low, High $x$ Medium, High x High. Clearly Low x Low region has the lowest risk, while the High $\mathrm{x}$ High region has the highest risk. The intermediate regions are more difficult to interpret because some regions are directly comparable and others are not (Altenbach, 1995)

In the Environmental Protection Agency in the USA (EPA) technical guidance for hazards analysis adapted by DOE-STD-3009-94, the risk levels from the 3 by 3 matrix are grouped into three categories: High (Major Concern), Medium (Concern) and Low (No Concern), as indicated in the Figure. 1 below, and also Table 1 shows the risk groupings from the EPA. 


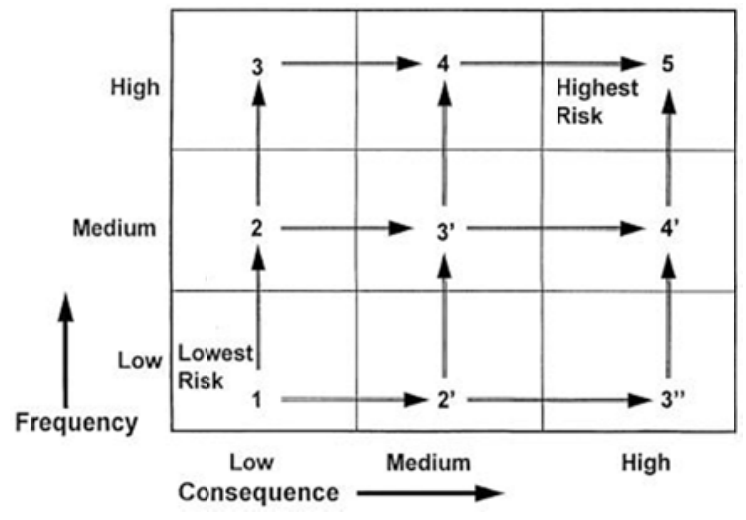

Fig. 2.Qualitative risk matrix: risk levels are relative to the regions connected by arrows (Altenbach, 1995)

It is notable in the figure above, that the arrows are designing directions from lower risk regions to higher risk regions. The relative risk of each region is given by a numerical grade, with 1 being the lowest and 5 the highest. Some regions with the same numerical grade are denoted by prime (') and double-prime (') to indicate that while they have the same relative risk level with respect to nearby regions connected by arrows, the risk of these regions is not necessarily equivalent, and may in fact be significantly different. The risk grade is only relative when applied to those regions directly connected by the arrows. For example, Medium x Low is risk grade 2 and is higher risk than Low $\mathrm{x}$ Low which is grade 1, and lower risk than High x Low (grade 3). And it is noted that High $\mathrm{x}$ Low and Medium x Medium have risk grade 3 and 3' respectively, but there is no implied equivalence between them. The only information common to both is that they have greater risk than Medium x Low and lower risk than High $\mathrm{x}$ Medium.

Table 1. Risk grouping from EPA (US Department of Energy, 1994)

\begin{tabular}{|llc|}
\hline Matrix Region & EPA Risk Grade & Figure 1 Risk Grade \\
\hline High*High & Major Concern & 5 \\
High*Medium & Major Concern & 4 \\
Medium*High & Major Concern & $4^{\prime}$ \\
\hline Medium*Medium & Concern & $3^{\prime}$ \\
Low*High & Concern & $3^{\prime \prime}$ \\
\hline High*Low & No Concern & 3 \\
Medium*Low & No Concern & 2 \\
Low*Medium & No Concern & $2^{\prime}$ \\
Low*Low & No Concern & 1 \\
\hline
\end{tabular}

The EPA grouping presents two types of logical inconsistencies, the first type of inconsistency places regions of different and directly comparable risk grade in the same group. Note the Major Concern group equates risk grade 4 and 5, and No Concern group equates risk grades 1,2 and one region of grade 3 . The second type of logical inconsistency places regions which are not directly comparable in the same group. Note the Concern group contains two risk grades 3 regions which are not directly comparable (US DOE, 1994).

It is also argued by Cox (personal communication, December 15, 2008), that risk matrices have limited ability to rank quantitative risks correctly and categorising the two axes of the matrix (e.g. frequency and severity or probability and consequence) often lead to inherently ambiguous risk classification.

\subsubsection{SEMI-quantitative matrix}

Few serious risk assessments actually use a purely qualitative approach, due to its limited usefulness. In an effort to enhance the usefulness of the comparative results, many semi-quantitative schemes have been tried. There are often referred to as qualitative methods, even though there is a quantitative foundation applied to the frequency axis, consequences axis, or even both (Cox, Babayev and Huber, 2005).

It is argued because of the limitations in making risk comparison, qualitative and semi-quantitative matrices have very limited value, it makes no sense to attempt risk groupings of the blocks (Cox, 2008: Brereton and Altenbach, 1998).

\subsubsection{Quantitative risk matrix}

Not all hazardous situations need to be analysed with a qualitative event tree/fault analysis. By making the consequences scale quantitative, even if only in relative dimensionless units, relative risk can be calculated for all regions in the matrix. A basic consistency requirement for qualitative and quantitative risk assessments is soundness, which states that higher quantitative risks should receive higher qualitative risk labels, or at least, should not receive lower ones (Cox, Babayev and Huber, 2005).Simmons et al (2005), argues that by using a quantitative risk matrix approach, each accident scenario will have a relative risk value associated with it, then all scenarios can be compared and ranked. Cox (2008), also states that, for the risk 
matrix to be most useful it should, at a minimum, discriminate reliability between very high and very low risks, so that it can be used as an effective screening tool to focus risk management attention and resources.

\section{NHS Risk Assessment}

The National Health Service (NHS) in the United Kingdom recognises the use of risk assessment matrix, and it is a tool used for making decisions on what control measures to be put in place according to the risk grade or ranking that is calculated by the risk assessment matrix. An essential part of the risk management process is to be able to measure the level of risk associated with a work activity or a workplace incident. Figure 3 below shows the risk assessment matrix that is widely used by the NHS.

\begin{tabular}{|c|c|c|c|c|c|}
\hline \multirow{2}{*}{ Likelihood } & \multicolumn{5}{|c|}{ Consequence } \\
\cline { 2 - 6 } & $\begin{array}{c}\text { Insignificant } \\
\text { (1) }\end{array}$ & Minor (2) & Moderate (3) & Major (4) & $\begin{array}{c}\text { Catastrophic } \\
\text { (5) }\end{array}$ \\
\hline Rare (1) & LOW & LOW & MODERATE & HIGH & HIGH \\
\hline Unlikely (2) & LOW & LOW & MODERATE & HIGH & EXTREME \\
\hline $\begin{array}{c}\text { Possible } \\
\text { (3) }\end{array}$ & LOW & MODERATE & HIGH & EX REME & EXTREME \\
\hline $\begin{array}{c}\text { Likely (4) } \\
\text { MODERATE }\end{array}$ & MODERATE & HIGH & EX REME & EXTREME \\
\hline $\begin{array}{l}\text { Almost } \\
\text { Certain (5) }\end{array}$ & MODERATE & HIGH & EXTREME & EX TREME & EXTREME \\
\hline
\end{tabular}

Fig. 3.NHS risk matrix available at (www.npsa.nhs.uk)

According to the NHS risk management strategy, If possible, the score of the likelihood will be by assigning a predicted frequency of occurrence of the adverse outcome. If this is not possible, a probability will be assigned to the adverse outcome occurring within a given time frame, such as the lifetime of a project or a patient care episode. If it is not possible to determine a numerical probability then the use of the probability descriptions will determine the most appropriate score (www.npsa.nhs.uk)

\section{Discussion}

Organisations are recommended to adopt a standard, defensible ranking system to allow for decision making, based on company's defined safety goals. The basic for risk ranking is the risk matrix that has consequence and frequency axis. The product of consequence and frequency provides a measure of risk.
Considering that groupings consisting of regions from different risk ratings are not logically consistent, and that groupings consisting of regions from the same risk rating are not logically consistent, one conclusion is clear, in general, logical groupings of regions of equivalent risk from the qualitative risk matrix cannot be found. To obtain the best use of risk matrix, each incident scenario is evaluated for the system being analysed and placed on the risk matrix in the appropriate region without any predefined risk acceptance levels or judgments. Then the analysts can define the risk acceptance levels by making subjective judgments based on the scenarios that fall in each region. On the other hand this process leaves the analyst open to criticism for adjusting the acceptance levels to suit some hidden agenda.

It is argued that the concept of probability is difficult to grasp and communicate, even though we are surrounded by examples of probability, such as lottery picks, the misunderstanding and misuse of the principles provide a wall which blocks the jump from the fuzzy comfortable qualitative realm to the precise yet uncertain quantitative realm.

In my experience within the NHS sector, Table 2 and 3 in Appendix A\& B, shows the possible descriptors for the consequences and the likelihood that, these classifications assist all NHS staff to be able to allocate numerical estimates of the risk, while avoiding any hidden agendas that the staff member/department may have. The risk matrix in the risk assessment forms standardise the process of grading the risk, as all staff are involved in the assessing of risks, having a simple risk matrix makes it easier for them to understand and locate the risk grading without any complexity which might put them off completing the risk assessment form. The NHS risk matrix also assists the risk managers, the board and all risk-owners to decide on the level of action that should be taken depending on the score.

Also, the quantitative approach can address numerical estimates of risk instead of some feeling like the scenario is safe. It can be used to analyse the cost/benefit tradeoffs of a risk reduction plan and address the perplexing question of "how safe is safe enough?” The increased utility of quantitative results will easily justify the extra bother in many applications.

According to Cox (2008), Many decision-makers and consultants believe that, while risk matrices may be only rough approximate tools for risk analysis, they are 
very useful for distinguishing qualitatively between the most urgent and least urgent risks in many settings and are certainly much better than doing nothing, for example, than purely random decision making. Donoghue (2001) also supports the idea that, the risk assessment matrices are effective tools in making decisions in regard to the control of occupational health risks. He states that, the control measures can be applied in an iterative fashion until the risk has been reduced to an acceptable residual.

The imagery of risk matrices is powerful, which may, along with their alleged and apparent simplicity, explain their popularity among agencies that are responsible for mainly lesser hazards, 1 and therefore are likely less qualified in risk, but who nonetheless feel the need to be seen to be proactive in managing risk. Inter alia, and as observed, though not sanctioned, in the new international guidance on risk assessment (ISO 31010), it is said that matrices are also widely used to determine if a risk posed by a given hazard is or is not acceptable.

Ball and Watt (2013) also concur with Cox (2008) that one of the leading arguments in support of risk matrices, which is that they are simple to use and transparent, is false. As determined here, all positionings of hazards on the matrix are subject to innumerable considerations, some of which even the rater may not be wholly aware. Yet, and it is another serious matter, requisite explanations and justifications are seldom, if ever, attempted.

It is this latter issue, of the consistency of use of risk matrices as applied to what are normally seen as beyond-the-workplace hazards. A growing number of authors, highly experienced in risk assessment, have questioned or had cause to investigate alleged shortcomings of risk matrices, mainly on technical grounds. In addition, standards-setting institutions have warned of the potential for subjectivity and inconsistencyas have researchers in occupational safety (Ball and Watt, 2013).

\section{Conclusion}

Risk assessment and risk management techniques are being developed in many fields as an aid to safety investment decision making. Expanding responsibilities and limited resources compel policy makers to make difficult choices about the prioritisation of risk reduction measure and what safety standards to aim for. The need for mechanisms to help policy makers set priorities has been increasingly felt, and during the last few decades techniques of risk assessment and philosophies of optimisation have been developed.

Risk matrices are very effective and widely used tool in making and improving risk management decisions, however the question of how ideally risk matrices should be constructed to improve risk management decisions is ongoing. It is not easy to answer, because risk matrices are typically used as only one component in informing eventual risk management decisions and also because their performance depends on the joint distribution of the two attributes probability and consequence.

A risk matrix can be a useful tool to present the results of simplified risk analysis, helping one to gain insight into the relative risk of various scenarios that might be encountered in a given system. When developed quantitatively with axes constructed to be relevant to the facility and operations being studied, risk evolutions can be defined logically. Logic based risk evaluations can facilitate management decisions such as the authorisation of operations. It can also help optimise resources by showing where to concentrate efforts for more detailed analysis or for risk reduction activities.

Using $3 x 3,4 \times 4$ or $5 \times 5$ matrix, will be useful to some organisations and might not be for others i.e. when $5 \times 5$ matrix is used, the matrix will have 25 blocks (risk grades), the more blocks for representation, the more likelihood of the risk matrix producing different levels which would produce more risk ranking grades. Therefore, organisations would be able to allocate the low, moderate, high and extreme risk groups to the appropriate levels of responsibilities within the organisations. The wider options for the probability and consequence scores on a risk matrix should give more scope to differentiate within the risk group the probability of a certain risk occurring and the consequence of the risk occurring within the low, moderate, high and extreme groups for the different levels of responsibility. whereas by having 3x3 matrix, there will be only 9 blocks for the risk grades, which in some cases might not be useful when making decisions or allocating resources.

However, if the descriptions of the consequence and likelihood scores are difficult to classify then the scores cannot always be well interpreted. For example, Table 1 
(appendix 1 NHS Risk Matrix), where it shows the consequence scores, by looking at the column where it says; Service Business Interruption; the difference between Major and Catastrophic scores; Catastrophic score leads the Business to a permanent loss of the business while Major score can only cause the business to be interrupted for one week. In such a case, the extreme description should be more than one week and permanent loss.

Cox (2009) argues that risk priority scoring systems, although widely used (and even required in many current regulations and standards), ignore essential information about correlations among risks. This information typically consists of noting common elements across multiple targets (e.g., common vulnerabilities).These common features induce common, or strongly positively correlated, uncertainties about the effectiveness of different risk-reducing measures. It is easy to use this information, in conjunction with well-known decision analysis and optimization techniques, to develop more valuable risk reduction strategies, for any given risk management budget, than can be expressed by a priority list. Thus, there appears to be abundant opportunity to improve the productivity of current risk-reducing efforts in many important applications using already well-understood optimization methods.To sum up, risk matrices are a useful way of ranking risks, but organisations should adjust the design and size of risk matrices to suit their needs.

\section{References}

1. Altenbach, $\mathrm{T}$ (1995). "A comparison of risk assessment Techniques from qualitative to quantitative”, proceedings of the joint ASMEIJSME pressure vessels and piping conference, Honolulu HI.

2. Altenbach, T \& Brereton S. (1998). "Risk Ranking Methodology for Chemical Release Events. Probabilistic Safety Assessment and Management. 4, International Conference on Probabilistic Safety Assessment and Management New York City, NY

3. Boyle, T. (2002). Health and safety: risk management. England: IOSH Services Limited

4. Cox, L. A. Jr., \& Huber, W. (2008). Optimal design of qualitative risk matrices to classify binary quantitative risks [abstract]. In: Proceedings of the Annual Meeting of the Society of Risk Analysis; 2008 December 7-10, Boston
5. Cox, L. A. Jr., Babayev, D., \&Huber,W. (2005). Some limitations of qualitative risk rating systems. Risk Analysis, 25(3), 651-662.

6. Cox, L. A. Jr. (2008). What is wrong with risk matrices?, Risk Analysis, Vol. 28, No. 2,

7. Donoghue, A, M. (2001). The design of hazard risk assessment matrices for ranking occupational health risk and their application in mining and minerals processing. Society of occupational medicine. Vol. 51 No. 2, pp 118-123

8. Dietz, T., Scott Frey, R. and Rosa, E. (1996) Risk, Technology, and Society, in: R.E. Dunlapand W. Michelson (eds) Handbook of Environmental Sociology, Westport: Greenwood Press.

9. Emblemsvag, J. \&Kjølstad, L.E. (2006), qualitative risk analysis: some problems and remedies. Management Decision, Vol. 44 No. 3

10. Fischhoff, B., Watson, S.R. and Hope, C. (1984) Defining risk, Policy Sciences 17, 123-29.

11. Glickman, T, S \& Gough, M. (1990). Readings in risk. USA: Resources For the Future

12. Kolluru, R.V \& Brooks, D.G. (1995) Integrated Risk Assessment and Strategic Management, in: R. Kolluru, S. Bartell, R. Pitblade and S. Stricoff (eds) Risk Assessment and Management Handbook. For Environmental, Health, and Safety Professionals, pp. 2.1-2.23, New York: McGraw-Hill.

13. Morgan, M.G. (1990) Choosing and Managing Technology-Induced Risks, in: T.S. Glickman and M. Gough (eds) Readings in Risk, pp. 5-15, Washington: Resources for the Future.

14. Markowski, A, S. \&Mannan, M, S. (2008). Fuzzy risk matrix. Journal of hazardous materials. pp 152-157

15. Mcilwain, J, C. (2006). A review : a decade of clinical risk management and risk tools. Journal of Clinician in Management, Volume 14, No 4, pp. 189-199(11)

16. Renn, O. (1998) Three decades of risk research: accomplishments and new challenges, Journal of Risk Research 1 (1), 49-71

17. Simmons, J.Dwyer, S \&Pfitzer, T. (2005). The RAC matrix: a universal tool or a toolkit. Journal of system safety. Vol. 41 No. 2. pp 14-19

18. Sunstein, C, R. (2000). Risk and reason: safety, law and the environment. England: Cambridge University Press

19. The Royal Society. (1992). Risk: analysis, perception and management. England: The Royal Society 
20. The National Patient Safety Agency (www.npsa.nhs.uk) accessed on 26th August 2013 at 17:40hrs

21. The International Risk Governance Council. (2005). White paper on Risk Governance: towards an Integrative Approach, can be downloaded from www.irgc.org

22. US Department of Energy. (1994). DOE Standard preparation guide for US Department of Energy Nonreactor Nuclear Facility Safety Analysis Reports, Washington, DC, DOE-STD-3009-94

23. Woodruff, J, M. (2005). Consequence and likelihood in risk estimation: A matter of balance in UK health and safety risk assessment practice. Safety Science. 43, 345-353

24. Ball, D. J. and Watt, J. (2013), Further Thoughts on the Utility of Risk Matrices. Risk Analysis, 33: 2068-2078

25. Cox, Jr., L. A. (2009), What's Wrong with HazardRanking Systems? An Expository Note. Risk Analysis, 29: 940-948

26. ISO (International Standards Organisation). Risk Management:Risk Assessment Techniques, 2009. ISO/IEC 31010.Geneva: ISO.

27. iNTeg-Risk (2013). iNTeg-Risk-Early Recognition, Mointoring and Integrated Management of Emerging, New Technology Related Risks (2007-2013), www.integrisk.eu-vri.eu 
Table 2. The Consequence scores used by the (National Patient Safety Agency in England)

\begin{tabular}{|c|c|c|c|c|c|}
\hline & 1 & 2 & 3 & 4 & 5 \\
\hline Descriptor & Insignificant & Minor & Moderate & Major & Catastrophic \\
\hline $\begin{array}{l}\text { Objectives / } \\
\text { Projects }\end{array}$ & $\begin{array}{l}\text { Insignificant cost } \\
\text { increase/schedule } \\
\text { slippage. Barely } \\
\text { noticeable reduction in } \\
\text { scope or quality }\end{array}$ & $\begin{array}{l}<\% \text { over } \\
\text { budget/schedule } \\
\text { slippage. Minor } \\
\text { reduction in } \\
\text { quality/scope } \\
\end{array}$ & $\begin{array}{l}5-10 \% \text { over } \\
\text { budge/schedule } \\
\text { slippage. Reduction } \\
\text { in scope or quality }\end{array}$ & $\begin{array}{l}10-25 \% \text { over } \\
\text { budget/schedule } \\
\text { slippage. Does not } \\
\text { meet secondary } \\
\text { objectives } \\
\end{array}$ & $\begin{array}{l}>25 \% \text { over } \\
\text { budget/schedule } \\
\text { slippage. Does not } \\
\text { meet primary } \\
\text { objectives }\end{array}$ \\
\hline Injury & $\begin{array}{l}\text { Minor injury not } \\
\text { requiring first aid }\end{array}$ & $\begin{array}{l}\text { Minor injury or } \\
\text { illness, first aid } \\
\text { treatment needed }\end{array}$ & $\begin{array}{l}\text { RIDDOR/Agency } \\
\text { reportable }\end{array}$ & $\begin{array}{l}\text { Major injuries or } \\
\text { long } \\
\text { incapacity/disability } \\
\text { (loss of limb) }\end{array}$ & $\begin{array}{l}\text { Death or major } \\
\text { permanent } \\
\text { incapacity }\end{array}$ \\
\hline $\begin{array}{l}\text { Patient } \\
\text { experience }\end{array}$ & $\begin{array}{l}\text { Unsatisfactory patient } \\
\text { experience not directly } \\
\text { related to patient care }\end{array}$ & $\begin{array}{l}\text { Unsatisfactory } \\
\text { patient experience - } \\
\text { readily resolvable }\end{array}$ & $\begin{array}{l}\text { Mismanagement of } \\
\text { patient care. }\end{array}$ & $\begin{array}{l}\text { Serious } \\
\text { mismanagement of } \\
\text { patient care }\end{array}$ & $\begin{array}{l}\text { Totally } \\
\text { unsatisfactory } \\
\text { patient outcome or } \\
\text { experience }\end{array}$ \\
\hline $\begin{array}{l}\text { Complaint/Cla } \\
\text { ims }\end{array}$ & Locally resolved & $\begin{array}{l}\text { Justified complaint } \\
\text { peripheral to clinical } \\
\text { care }\end{array}$ & $\begin{array}{l}\text { Below excess claim. } \\
\text { Justified complaint } \\
\text { involving lack of } \\
\text { appropriate care }\end{array}$ & $\begin{array}{l}\text { Claim above excess } \\
\text { level. Multiple } \\
\text { justified complaints }\end{array}$ & $\begin{array}{l}\text { Multiple claims or } \\
\text { single major claim }\end{array}$ \\
\hline $\begin{array}{l}\text { Service } \\
\text { business } \\
\text { interruption }\end{array}$ & $\begin{array}{l}\text { Loss/interruption > } 1 \\
\text { hour }\end{array}$ & $\begin{array}{l}\text { Loss/interruption }>8 \\
\text { hours }\end{array}$ & $\begin{array}{l}\text { Loss/interruption }>1 \\
\text { day }\end{array}$ & $\begin{array}{l}\text { Loss/interruption }>1 \\
\text { week }\end{array}$ & $\begin{array}{l}\text { Permanent loss of } \\
\text { service of facility }\end{array}$ \\
\hline $\begin{array}{l}\text { Staffing \& } \\
\text { competence }\end{array}$ & $\begin{array}{l}\text { Short-term low staffing } \\
\text { level temporarily reduces } \\
\text { service quality ( }<1 \text { day) }\end{array}$ & $\begin{array}{l}\text { Ongoing low } \\
\text { staffing level } \\
\text { reduces service } \\
\text { quality }\end{array}$ & $\begin{array}{l}\text { Late delivery of key } \\
\text { objective/service } \\
\text { due to lack of staff. } \\
\text { Minor error due to } \\
\text { poor training. } \\
\text { Ongoing unsafe } \\
\text { staffing level. }\end{array}$ & $\begin{array}{l}\text { Uncertain delivery } \\
\text { of key } \\
\text { objective/service } \\
\text { due to lack of staff. } \\
\text { Serious error due to } \\
\text { poor training }\end{array}$ & $\begin{array}{l}\text { Non-delivery of key } \\
\text { objective/service } \\
\text { due to lack of staff. } \\
\text { Loss of key staff. } \\
\text { Critical error due to } \\
\text { insufficient training }\end{array}$ \\
\hline Financial & Small loss & $\begin{array}{l}\text { Loss }>0.1 \% \text { of } \\
\text { budget }\end{array}$ & $\begin{array}{l}\text { Loss }>0.25 \% \text { of } \\
\text { budget }\end{array}$ & Loss $>0.5$ of budget & Loss $>1 \%$ of budget \\
\hline $\begin{array}{l}\text { Inspection/aud } \\
\text { it }\end{array}$ & $\begin{array}{l}\text { Minor recommendations } \\
\text { Minor Non-compliance } \\
\text { with standards }\end{array}$ & $\begin{array}{l}\text { Recommendations } \\
\text { given. Non- } \\
\text { compliance with } \\
\text { standards }\end{array}$ & $\begin{array}{l}\text { Reducing rating. } \\
\text { Challenging } \\
\text { recommendations. } \\
\text { Non-compliance } \\
\text { with core standards }\end{array}$ & $\begin{array}{l}\text { Enforcement } \\
\text { Action. Low rating. } \\
\text { Critical report. } \\
\text { Major non- } \\
\text { compliance with } \\
\text { core standards } \\
\end{array}$ & $\begin{array}{l}\text { Prosecution. Zero } \\
\text { rating. Severely } \\
\text { critical report }\end{array}$ \\
\hline $\begin{array}{l}\text { Adverse } \\
\text { publicity/reput } \\
\text { ation }\end{array}$ & Rumours & $\begin{array}{l}\text { Local media - short } \\
\text { term. Minor effect } \\
\text { on staff morale }\end{array}$ & $\begin{array}{l}\text { Local media - long } \\
\text { term. Significant } \\
\text { effect on staff } \\
\text { morale }\end{array}$ & $\begin{array}{l}\text { National media }<3 \\
\text { days }\end{array}$ & $\begin{array}{l}\text { National Media }>3 \\
\text { days. MP concern } \\
\text { (question in House } \\
\text { of parliament) }\end{array}$ \\
\hline
\end{tabular}

Table 3. The Likelihood scores

\begin{tabular}{|c|c|c|c|c|c|}
\hline & 1 & 2 & 3 & 4 & 5 \\
\hline Descriptor & Rare & Unlikely & Possible & Likely & Almost certain \\
\hline Frequency & $\begin{array}{l}\text { Not expected to } \\
\text { occur for years. }\end{array}$ & $\begin{array}{l}\text { Expected to occur at } \\
\text { least annually. }\end{array}$ & $\begin{array}{l}\text { Expected to occur at } \\
\text { least monthly. }\end{array}$ & $\begin{array}{l}\text { Expected to occur at } \\
\text { least weekly. }\end{array}$ & $\begin{array}{l}\text { Expected to occur at } \\
\text { least daily. }\end{array}$ \\
\hline & $<1 \%$ & $1-5 \%$ & $6-20 \%$ & $21-50 \%$ & $>50 \%$ \\
\hline Probability & $\begin{array}{l}\text { Will occur in } \\
\text { exceptional } \\
\text { circumstances. }\end{array}$ & Unlikely to occur. & $\begin{array}{l}\text { Reasonable chance } \\
\text { of occurring. }\end{array}$ & Likely to occur. & $\begin{array}{l}\text { More likely to occur } \\
\text { than not. }\end{array}$ \\
\hline
\end{tabular}

